\title{
Comparing Two Types of Endometrial Scratch Before Embryo Transfer: A Prospective Randomized Pilot Study
}

Kathryn M Goldrick ( $\sim$ goldrick@uthscsa.edu )

University of Texas Health Science Center at San Antonio

Paul B Marshburn

Carolinas Medical Center

Michelle L Matthews

Carolinas Medical Center

Rebecca S Usadi

Carolinas Medical Center

Margaret A Papadakis

Carolinas Medical Center

Bradley S Hurst

Carolinas Medical Center

\section{Research Article}

Keywords: endometrial scratch, assisted reproductive technology, in vitro fertilization

Posted Date: November 1st, 2021

DOI: https://doi.org/10.21203/rs.3.rs-923387/v1

License: (1) This work is licensed under a Creative Commons Attribution 4.0 International License.

Read Full License 


\section{Comparing Two Types of Endometrial Scratch before Embryo Transfer: A Prospective Randomized Pilot Study}

Authors: Kathryn M Goldrick ${ }^{1,2}$, Paul B Marshburn ${ }^{1}$, Michelle L Matthews ${ }^{1}$, Rebecca S Usadi ${ }^{1}$, Margaret A Papadakis ${ }^{1}$, Bradley S Hurst ${ }^{1}$

${ }^{1}$ Carolinas Medical Center, 1025 Morehead Medical Drive, Charlotte NC 28204 kathryn.goldrick@gmail.com paul.marshburn@atriumhealth.org michelle.matthews@atriumhealth.org rebecca.usadi@atriumhealth.org mpap@carolina.rr.com brad.hurst@atriumhealth.org

${ }^{2}$ University of Texas Health Science Center at San Antonio, 7703 Floyd Curl Drive, San Antonio TX 78229

Corresponding Author: Kathryn Goldrick kathryn.goldrick@gmail.com 704-619-3264

7703 Floyd Curl Drive MC 7836, San Antonio TX 78229 


\begin{abstract}
$\underline{\text { Abstract }}$
Purpose: Although endometrial scratch may improve outcomes in certain groups of women undergoing assisted reproductive technology (ART), the type of endometrial procedure has not been specified. Our objective was to determine if two types of endometrial scratch prior to embryo transfer result in similar implantation and live birth rates. Also, to determine if patients experience similar pain from both types of endometrial scratch.

Methods: This was a prospective, non-blinded, randomized controlled trial with parallel treatment arms of women undergoing blastocyst embryo transfer. Patients underwent endometrial scratch with either vigorous Pipelle curette or four-quadrant scratch with the Shepard insemination catheter.

Results: There were 78 patients in the Pipelle curette group and 92 in the Shepard catheter group. There was no difference in implantation rates for the two groups $(56.5 \% \pm 48$ for Pipelle curette group vs. 59.7\% \pm 52 for Shepard catheter group, p-value 0.9 ). Live birth rates were also similar for the two groups $(48.1 \% \pm 50$ for Pipelle curette group vs. $46.8 \% \pm 50$ for Shepard catheter group, p-value 0.7). Mean pain score was significantly less for the Shepard catheter group than for the Pipelle curette group (3.0 \pm 2.4 vs. $3.9 \pm 2.2$, p-value 0.01$)$.

Conclusions: Our study demonstrates no difference in implantation or live birth rates for two types of endometrial scratch. There was a difference in patient pain scales with endometrial scratch by a Shepard insemination catheter having a significantly lower pain score than by Pipelle curette. This data gives guidance as to the type of endometrial scratch to be performed prior to ART.
\end{abstract}

Key Words: endometrial scratch, assisted reproductive technology, in vitro fertilization

\title{
$\underline{\text { Introduction }}$
}

Despite advances in assisted reproductive technologies (ART) that have improved clinical outcome following in vitro fertilization (IVF) over the past three decades, clinical pregnancy rate and live birth rate remain $45-55 \%$ and $35-45 \%$, respectively (1). Implantation is essential for successful ART and IVF procedures, and many interventions have been studied to possibly improve implantation rates and thus pregnancy and live birth rates (2).

Endometrial scratch is one such intervention, and it is defined by the Cochrane Collaboration as "intentional endometrial injury, such as endometrial biopsy or curettage, in women undergoing ART" (3). The mechanism of possible increased endometrial receptivity as a result of endometrial scratch is still unknown; however, three proposed hypotheses exist. The first hypothesis is that local trauma to the endometrium induces effects on endometrial decidualization to facilitate embryo implantation $(4,5,6)$. The second hypothesis is that endometrial healing following endometrial scratch involves activation of a cytokine, interleukin, growth factor, macrophage, and dendritic cell cascade that are beneficial to embryo implantation $(4,57,8,9)$. The final hypothesis is that endometrial scratch may favorably alter endometrial maturation to improve synchronicity between the endometrium and the embryo implantation $(4,5,10,11$,$) .$

A Cochrane Review which examined endometrial scratch prior to IVF concluded that endometrial scratch prior to the embryo transfer cycle significantly improves clinical pregnancy rates and live birth rates in women undergoing ART. Although the type of endometrial procedure is not specified, the timing of endometrial scratch was found be most effective when performed 
in the cycle prior to the embryo transfer $(3,4)$. More recently, a multi-center randomized control trial of 1,364 women who were randomized to either endometrial scratch or no intervention in the cycle prior to embryo transfer demonstrated no differences in rates of ongoing pregnancy, clinical pregnancy, multiple pregnancy, ectopic pregnancy, or miscarriage between the two groups (12). This has led to uncertainty and debate about the value of endometrial scratch in ART (13-21). However, other studies have proposed that there may be a role for endometrial scratch in specific groups of patients undergoing ART, particularly those with a history of multiple embryo transfer failures (22-33).

Although endometrial scratch prior to embryo transfer may have benefit in pregnancy and live birth rates in certain groups of patients $(3,4)$, no specification of the best technique has been determined. Endometrial biopsy, curette, touch, and hysteroscopy have all been used in studies for endometrial scratch since they all induce mechanical disruption of the endometrium $(22,27)$. The most recent Cochrane review, however, noted that the endometrial scratch methods of endometrial injury were associated with significant pain for patients (4). Therefore, therapeutic intervention that both enhance pregnancy rates and result in less patient pain is optimally important. Our objective was to compare two types of endometrial scratch - an endometrial biopsy with a Pipelle curette versus a four-quadrant endometrial scratch using a Shepard insemination catheter - to determine if the live birth rates are equivalent for the two methods. We also compared patient pain scores between the two types of endometrial scratch. By comparing two distinct types of endometrial scratch, we hoped to determine which method is both effective and tolerable to patients.

\section{Materials and Methods}

\section{$\underline{\text { Study Design and Participants }}$}

This was a non-blinded prospective, randomized controlled trial, conducted between 2014 and 2017, with parallel treatment arms performed at Carolinas Medical Center's Women's Institute, an academic fertility center. We included all patients undergoing embryo transfer who were in the cycle prior to their planned embryo transfer. Exclusion criteria included patients not undergoing an embryo transfer, known pregnancy, active pelvic infection, known endometrial hyperplasia or cancer, inability to tolerate endometrial catheter placement, severe cervical stenosis, and patients who were planned for operative hysteroscopy in the cycle prior to embryo transfer.

\section{Ethics Approval and Desire to Participate}

After Institutional Review Board approval was obtained from the Atrium Health IRB committee (IRB00001088, IRB00001103), informed consent was obtained from study participants. All methods were performed in accordance with the relevant guidelines and regulations.

\section{Randomization}

After patients were enrolled in the study, their demographic data was collected. Patients were then randomized by a random number generator for allocation to either: 1) endometrial biopsy 
with a Pipelle curette or 2) four-quadrant endometrial scratch with a Shepard insemination catheter.

\section{Endometrial Scratch Technique}

The Pipelle is semi-rigid endometrial biopsy catheter with an internal stylet plunger, which possesses a $3.1 \mathrm{~mm}$ tip diameter (Cooper Surgical $\left.{ }^{\circledR}\right)$. Endometrial scratch by endometrial biopsy using the Pipelle curette is well described in the literature. To our knowledge, endometrial scratch using a Shepard catheter (Cook Medical $\left.{ }^{\circledR}\right)$ is a novel technique. The Shepherd catheter is a $1.8 \mathrm{~mm}$ malleable insemination catheter that can be curved to traverse the cervix. It is also used by some physicians to perform saline infusion sonography (SIS). It was chosen as a method for endometrial scratch because the Shepard catheter has a smaller tip diameter, is more pliant, can be shaped to accommodate a tortuous endocervical canal, and is often used in our clinic for the performance of saline infusion sonography with disruption of the endometrium seen on ultrasound.

During the cycle before embryo transfer, women were scheduled between cycle days 2127 for the endometrial scratch procedure. For the Pipelle curette group, physicians inserted the Pipelle curette into the top of the intrauterine cavity and removed an adequate endometrial sample by applying suction with catheter rotation during withdrawal. For the Shepard catheter group, physicians performed a four-quadrant scratch technique by inserting the Shepard insemination catheter to the top of the uterine cavity, and then rotating quarter turns to touch and disrupt the endometrium at 12:00. 3:00, 6:00, and 9:00 o'clock positions on the clock-face. Immediately following the endometrial procedure, patients were given a Numerical Rating Scale (NRS) for pain.

\section{$\underline{\text { ART Cycles }}$}

The remainder of the IVF cycle and embryo transfer proceeded by standard protocol. Data was collected including information about the embryos, embryo transfer, implantation rate, positive pregnancy test, and live birth rate.

\section{$\underline{\text { Statistical Methods }}$}

Based on an $80 \%$ power calculation in which a $10 \%$ change in live birth rate was deemed to be clinically significant, the sample size needed to attain adequate power was found to be 200 total patients. Statistical analysis was performed in collaboration with statisticians from Carolina Medical Center's Dickson Advanced Analytics and using DA2 software. This data was found to be normally distributed, so means, standard deviations, and p-values found using Chi-squared testing were used for analysis. P-values less than 0.05 were considered statistically significant. Subgroup analysis was performed comparing implantation rate for the two study groups and stratifying fresh and frozen embryo transfer, PGT-A and unscreened embryos, AMH $<1$ and $\mathrm{AMH} \geq 1$, and single and two embryos transferred.

\section{Clinical Trial Registration}


As a randomized control trial, this study closely adhered to the guidelines of CONSORT 2010. A CONSORT statement was completed, and the trial was registered with the NIH Clinical Trials Platform - study NCT04363879 was registered on 04/27/20.

\section{$\underline{\text { Results }}$}

There were 162 subjects who were recruited, and 29 of these patients were re-randomized in subsequent embryo transfer cycles. Thus 195 transfers were included in this study. Twentyfive cycles were excluded for cervical stenosis, patient intolerance of procedure, patient drop-out of study, and no available embryos for transfer. This gave a total of 170 transfers. Seventy-eight patients were randomized to the Pipelle endometrial scratch group, and 92 patients were randomized to the Shepard catheter endometrial scratch group (Supplemental Figure 1).

Demographic data was compared between the two groups, and no significant differences were found (Table 1).

Table 1. Demographic data compared between study groups. Show as mean \pm standard deviation.

\begin{tabular}{|l|c|c|c|}
\hline & $\begin{array}{c}\text { Pipelle } \\
(\mathrm{n}=78)\end{array}$ & $\begin{array}{c}\text { Shepard } \\
(\mathrm{n}=92)\end{array}$ & p-value \\
\hline Maternal Age & $33.8 \pm 4.6$ & $34.2 \pm 3.9$ & 0.6 \\
\hline BMI & $24.9 \pm 4.3$ & $24.8 \pm 5.5$ & 0.9 \\
\hline $\begin{array}{l}\text { Number Prior } \\
\text { Pregnancies }\end{array}$ & $0.9 \pm 1.1$ & $1.1 \pm 1.3$ & 0.3 \\
\hline $\begin{array}{l}\text { Number Prior Live } \\
\text { Births }\end{array}$ & $0.4 \pm 0.7$ & $0.4 \pm 0.6$ & 0.9 \\
\hline AMH & $4.2 \pm 3.3$ & $4.4 \pm 4.0$ & 0.9 \\
\hline
\end{tabular}

The ART cycle characteristics were also compared between the two study groups, and no significant differences were found (Table 2, Table 3 ).

Table 2. ART cycle characteristics compared between study groups. Shown as N (\% of population).

\begin{tabular}{|c|c|c|}
\hline & $\begin{array}{c}\text { Pipelle } \\
(\mathrm{n}=78)\end{array}$ & $\begin{array}{c}\text { Shepard } \\
(\mathrm{n}=92)\end{array}$ \\
\hline PGT-A/PGT-D & $27(35)$ & $37(42)$ \\
Screened & $50(65)$ & $52(58)$ \\
Unscreened & $1(1)$ & $2(2)$ \\
\hline Type Cycle & $77(99)$ & $90(98)$ \\
Fresh & $5(6)$ & $6(7)$ \\
Frozen & $0(0)$ & $3(3)$ \\
\hline Donor Egg & $77(100)$ & $85(97)$ \\
\hline Type freezing & & \\
Slow Freeze & Vitrification & \\
\hline
\end{tabular}


Table 3. ART cycle characteristics compared between study groups. Shown as mean \pm standard deviation.

\begin{tabular}{|l|c|c|c|}
\hline & $\begin{array}{c}\text { Pipelle } \\
(\mathrm{n}=78)\end{array}$ & $\begin{array}{c}\text { Shepard } \\
(\mathrm{n}=92)\end{array}$ & p-value \\
\hline $\begin{array}{l}\text { Number Eggs } \\
\text { Retrieved }\end{array}$ & $17.8 \pm 9.0$ & $19.1 \pm 10.3$ & 0.4 \\
\hline $\begin{array}{l}\text { Number Eggs } \\
\text { Fertilized }\end{array}$ & $10.9 \pm 5.7$ & $11.1 \pm 6.7$ & 0.8 \\
\hline $\begin{array}{l}\text { Number Embryos } \\
\text { Transferred }\end{array}$ & $1.1 \pm 0.2$ & $1.1 \pm 0.3$ & 0.2 \\
\hline
\end{tabular}

Finally, the ART results were compared between study groups - clinical pregnancy rate, implantation rate, and live birth rate were similar between the two groups. However, pain rated by NRS after the endometrial scratch procedure was found to be significantly less in the Shepard catheter group than in the Pipelle curette group $(3.9 \pm 2.2$ vs. $3.0 \pm 2.4$, p 0.01) (Table 4).

Table 4. ART results and pain compared between study groups. Shown as mean \pm standard deviation.

\begin{tabular}{|l|c|c|c|}
\hline & $\begin{array}{c}\text { Pipelle Curette } \\
(\mathrm{n}=78)\end{array}$ & $\begin{array}{c}\text { Shepard Catheter } \\
(\mathrm{n}=92)\end{array}$ & p-value \\
\hline $\begin{array}{l}\text { Clinical Pregnancy } \\
\text { Rate }\end{array}$ & $71.8 \% \pm 45$ & $67.6 \% \pm 47$ & 0.6 \\
\hline Implantation rate & $56.5 \% \pm 48$ & $59.7 \% \pm 52$ & 0.9 \\
\hline Live birth rate & $48.1 \% \pm 50$ & $46.8 \% \pm 50$ & 0.7 \\
\hline Pain & $3.9 \pm 2.2$ & $3.0 \pm 2.4$ & $\mathbf{0 . 0 1}$ \\
\hline
\end{tabular}

Certain factors influence ART results, particularly fresh vs frozen embryo transfer, PGT screening, AMH, and single vs two embryos transferred. Our results were stratified to account for these variables, and implantation rates were compared between the two study groups. No significant differences in implantation rate were found when the results were stratified. Of note, we were not able to analyze the stratification of fresh embryo transfers between the two study groups because there were only 3 fresh transfers total performed (Supplemental Table 1).

\section{$\underline{\text { Discussion }}$}

This study demonstrates no difference in pregnancy, implantation, or live birth rates when endometrial scratch was performed with a Pipelle curette or a Shepard catheter in the cycle prior to an embryo transfer. There was, however, a difference in patient pain scores, and endometrial scratch with the Shepard catheter was significantly less painful than with the Pipelle curette.

One possible mechanism for patients' decreased pain with the Shepard catheter is the smaller diameter $1.8 \mathrm{~mm}$ compared with the Pipelle catheter's diameter $3.1 \mathrm{~mm}$. The Shepard catheter is malleable while the Pipelle curette is semi-rigid. Both of these factors may contribute to decreased pain since the catheters must pass through the cervix for endometrial scratch. Additionally, the endometrial scratch procedure for the Pipelle curette involves removal of endometrial tissue, whereas endometrial scratch with the Shepard catheter involves only 
endometrial disruption. A prior study found that women's mean pain from an endometrial biopsy using the Pipelle curette was $6.2 \pm 2.4$ on a visual analog scale from 1-10 (34). The mean pain score for patients in our study who underwent endometrial scratch with the Pipelle catheter was found to be $3.9 \pm 2.2$ which is even lower than as found in Leclair's study. Pain with the Shepard catheter has not been previously studied.

We chose to study endometrial scratch with the Pipelle curette and the Shepard catheter because they can both be performed in office, are relatively quick and easy to use, and incur minimal cost to the patients. Because the Shepard catheter may be used for saline infusion sonogram, we most commonly select a single patient visit during the cycle preceding the ovarian stimulation for IVF. At that time, we accomplish the following procedures in order: 1) trial transfer with a soft embryo transfer catheter, then 2) a saline infusion sonogram with the Shepard catheter using the adjustable sliding positioner of the Shepard catheter to limit fluid back flow, followed by 3) the four quadrant Shepard catheter endometrial scratch. All of this is accomplished in one patient visit with a single speculum exam. This practice optimizes patient convenience, lowers procedural costs, and reduces the overall discomfort involved in multiple pelvic exams. Some studies have suggested that hysteroscopy is another means of performing endometrial scratch, but this modality is more costly, invasive, and time consuming than the two types of endometrial scratch that we chose to study.

To our knowledge, this is the first study which compares outcome measures between two types of endometrial scratch procedures, one of which, the Pipelle, is the most commonly used catheter for endometrial scratch. Strengths of this study include that it is a randomized control trial, many variables were collected to analyze confounding factors, and it is powered to detect a difference in live birth rate. The reporting of live birth rate data is very important to assess complications which may not affect clinical pregnancy rates but impact the final event hoped for by any patient undergoing ART. There are several limitations of this study. First, the study population had a relatively small sample size, and so larger randomized controlled trials are needed to confirm our findings. Secondly, the study was not blinded. The objective outcome measures (clinical pregnancy, live birth rate), patient assessment of pain scores should be minimally impacted by blinding, however. Thirdly, there was a little more that $10 \%$ of patients excluded for the following reasons cervical stenosis, patient intolerance of procedure, patient drop-out of study, and no available embryos for transfer. The randomization process should serve to limit the bias from these exclusions. Additionally, there were only 3 total fresh transfers performed, so the results of this study may not be generalizable to fresh embryo transfers. The greater proportion of frozen embryo transfers in this study does reflect a trend within the field toward frozen embryo transfers, particularly with the greater utilization of PGT.

\section{Conclusions}

The value of endometrial scratch for improving ART cycle pregnancy rates is supported by the most recent Cochrane analysis (4), however, debate continues to exists about the value of endometrial scratch prior to embryo transfer. It is becoming increasingly evident with emerging literature that endometrial scratch may not improve ART outcomes for all patients who undergo embryo transfer, but a population of patients most likely to benefit from endometrial scratch prior to embryo transfer would be couples with recurrent implantation failures $(22,23)$. Despite current research surrounding endometrial scratch, no uniform technique has been described. Our 
study provides data that endometrial scratch performed with the Shepard catheter had equivalent ART results but was significantly less painful than endometrial scratch performed with the Pipelle curette. Thus, when endometrial scratch is performed, a technique using the Shepard catheter is preferred over using a Pipelle catheter.

None.

\section{Acknowledgements:}

\section{$\underline{\text { References }}$}

1. Centers for Disease Control and Prevention Assisted Reproductive Technology National Summary Report. https://www.cdc.gov/art/reports/2016/national-summary-figures.html. (14 April 2020, date last accessed) 2016.

2. Barash A, Dekel N, Fieldust S, Segal I, Schechtman E, Granot I. Local injury to the endometrium doubles the incidence of successful pregnancies in patients undergoing in vitro fertilization. Fertil Steril 2003;79(6):1317-22.

3. Nastri CO, Gibreel A, Raine-Fenning N, Maheshwari A, Ferriani RA, Bhattacharya S, Martins WP. Endometrial injury in women undergoing assisted reproductive techniques (review). Cochrane Collaboration 2012;7:1-43.

4. Nastri CO, Lensen SF, Gibreel A, Raine-Fenning N, Ferriani RA, Bhattacharya S, Martins WP. Endometrial injury in women undergoing assisted reproductive techniques. Cochrane Database of Systematic Review 2015;3:CD009517.

5. Li R, Hao G. Local injury to the endometrium: its effect on implantation. Current Opinion in Obstetrics and Gynecology 2009;21(3):236-9.

6. Zhou L, Li R, Wang R, Huang HX, Zhong K. Local injury to the endometrium in controlled ovarian hyperstimulation cycles improves implantation rates. Fertility and Sterility 2008;89(5):1166-76.

7. Siristatidis C, Vrachnis N, Vogiatzi P, Chrelias C, Retamar AQ, Bettocchi S, et al. Potential pathophysiological mechanisms of the beneficial role of endometrial injury in in vitro fertilization outcome. Reproductive Sciences 2014;21(8):955-65.

8. Gnainsky Y, Granot I, Aldo PB, Barash A, Or Y, Schechtman E, et al. Local injury of the endometrium induces an inflammatory response that promotes successful implantation. Fertility and Sterility 2010;94(6):2030-6.

9. Junovich G, Mayer Y, Azpiroz A, Daher S, Iglesias A, Zylverstein C, et al. Ovarian stimulation affects the levels of regulatory endometrial NK cells and angiogenic cytokine VEGF. American Journal of Reproductive Immunology 2011;65(2):146-53.

10. Lass A, Peat D, Avery S, Brinsden P. Histological evaluation of endometrium on the day of oocyte retrieval after gonadotrophin-releasing hormone agonist-follicle stimulating hormone ovulation induction for in-vitro fertilization. Human Reproduction 1998;13(11):3203-5.

11. Ubaldi F, Bourgain C, Tournaye H, Smitz J, Steirteghem A, Devroey P. Endometrial evaluation by aspiration biopsy on the day of oocyte retrieval in the embryo transfer cycles in patients with serum progesterone rise during the follicular phase. Fertility and Sterility 1997;67(3):521-6. 
12. Lensen S, Osavlyuk D, Armstrong S, Stadelmann C, Hennes A, Napier E, et al. A randomized trial of endometrial scratching before in vitro fertilization. N Engl J Med 2019;380(4):325-334.

13. Vitagliano A, Andrisani A, Alviggi C, Vitale SG, Valenti G, Sapia F, et al. Endometrial scratch for infertile women undergoing a first embryo transfer: a systematic review and meta-analysis of published and unpublished data from randomized control trials. Fertil Steril 2019;111(4): 734-46.

14. Karimzade MA, Oskouian H, Ahmadi S, Oskouian L. Local injury to the endometrium on the day of oocyte retrieval has a negative impact on implantation in assisted reproductive cycles: a randomized controlled trial. Arch Gynecol Obstet 2010;281:499_ 503.

15. Yeung TW, Chai J, Li RH, Lee VC, Ho PC, Ng EH. The effect of endometrial injury on ongoing pregnancy rate in unselected subfertile women undergoing in vitro fertilization: a randomized controlled trial. Hum Reprod 2014;29: 2474-81.

16. Mahran A, Ibrahim M, Bahaa $H$. The effect of endometrial injury on first cycle IVF/ICSI outcome: a randomized controlled trial. Int J Reprod Biomed 2016;14:193-8.

17. Maged AM, Rashwan H, AbdelAziz S, Ramadan W, Mostafa WAI, Metwally AA, et al. Randomized controlled trial of the effect of endometrial injury on implantation and clinical pregnancy rates during the first ICSI cycle. Int J Gynaecol Obstet 2018;140:2116.

18. Liu W, Tal R, Chao H, Liu M, Liu Y. Effect of local endometrial injury in proliferative vs. luteal phase on IVF outcomes in unselected subfertile women undergoing in vitro fertilization. Reprod Biol Endocrinol 2017;15:75.

19. Polanski LT, Raine-Fenning N. A study to assess if scratching the lining of the womb prior to IVF treatment increases the chances of pregnancy. NCT01882842. ClinicalTrials.gov; 2018. https://clinicaltrials.gov/ct2/show/NCT01882842. Accessed February 28, 2020.

20. Nastri CO, Ferriani RA, Raine-Fenning N, Martins WP. Endometrial scratching performed in the non-transfer cycle and outcome of assisted reproduction: a randomized controlled trial. Ultrasound Obstet Gynecol 2013;42:375-82.

21. Van Hoogenhijze NE, Kasius JC, Broekmans FJM, Bosteels J, Torrance HL. Endometrial scratching prior to IVF; does it help and for whom? A systematic review and metaanalysis. Hum Reprod Open 2019.2019(1):1-18.

22. Potdar N, Gelbaya T, Nardo LG. Endometrial injury to overcome embryo implantation failure: a systematic review and meta-analysis. Reprod BioMedicine Online 2012;25: 561-71.

23. Vitagliano A, Di Spiezio Sardo A, Saccone G, Valenti G, Sapia F, Kamath MS, et al. Endometrial scratch injury for women with one or more previous failed embryo transfers: a systematic review and meta-analysis of randomized control trials. Fertil Steril 2018; 110(4):687-702.

24. Karimzadeh MA, Ayazi Rozbahani M, Tabibnejad N. Endometrial local injury improves the pregnancy rate among recurrent implantation failure patients undergoing in vitro fertilisation/intra cytoplasmic sperm injection: a randomized clinical trial. Aust N Z J Obstet Gynaecol 2009;49: 677-80.

25. Narvekar SA, Gupta N, Shetty N, Kottur A, Srinivas M, Rao KA. Does local endometrial injury in the nontransfer cycle improve the IVF-ET outcome in the subsequent cycle in 
patients with previous unsuccessful IVF? A randomized controlled pilot study. J Hum Reprod Sci 2010;3:15-9.

26. Inal ZHO, Gorkemli H, Inal HA. The effect of local injury to the endometrium for implantation and pregnancy rates in ICSI-ET cycles with implantation failure: a randomized controlled study. Eur J Gen Med 2012;9(4):223-9.

27. Shohayeb A, El-Khayat W. Does a single endometrial biopsy regimen (SEBR) improve ICSI outcome in patients with repeated implantation failure? A randomized controlled trial. Eur J Obstet Gynecol Reprod Biol 2012;164:176-9.

28. Singh N, Toshyan V, Kumar S, Vanamail P, Madhu M. Does endometrial injury enhance implantation in recurrent in-vitro fertilization failures? A prospective randomized control study from tertiary care center. J Hum Reprod Sci 2015;8:218-23.

29. Gibreel A, El-Adawi N, Elgindy E, Al-Inany H, Allakany N, Tournaye H. Endometrial scratching for women with previous IVF failure undergoing IVF treatment. Gynecol Endocrinol 2015;31:313-6.

30. Baum M, Yerushalmi GM, Maman E, Kedem A, Machtinger R, Hourvitz A, et al. Does local injury to the endometrium before IVF cycle really affect treatment outcome? Results of a randomized placebo controlled trial. Gynecol Endocrinol 2012;28:933-6.

31. Shahrokh-Tehraninejad E, Dashti M, Hossein-Rashidi B, Azimi-Nekoo E, Haghollahi F, Kalantari V. A randomized trial to evaluate the effect of local endometrial injury on the clinical pregnancy rate of frozen embryo transfer cycles in patients with repeated implantation failure. J Family Reprod Health 2016;10:108-14.

32. Aleyamma TK, Singhal H, S Premkumar P, Acharya M, S Kamath M, George K. Local endometrial injury in women with failed IVF undergoing a repeat cycle: a randomized controlled trial. Eur J Obstet Gynecol Reprod Biol 2017;214:109-14.

33. Mak JSM, Chung CHS, Chung JPW, Kong GWS, Saravelos SH, Cheung LP, et al. The effect of endometrial scratch on natural-cycle cryopreserved embryo transfer outcomes: a randomized controlled study. Reprod Biomed Online 2017;35:28-36.

34. Leclair CM, Zia JK, Doom CM, Morgan TK, Edelman AB. Pain experienced using two different methods of endometrial biopsy: a randomized control trial. Obstet Gynecol 2011;117(3):636-41. 


\section{Supplementary Files}

This is a list of supplementary files associated with this preprint. Click to download.

- EndoScratchSupplementaryTable.docx

- SupplementalFigure1.docx 